Revista do Departamento de Geografia
Universidade de São Paulo
www.revistas.usp.br/rdg
Volume Especial (2016)

\title{
EVENTOS EXTREMOS PLUVIAIS EM JABOATÃO DOS GUARARAPES: CLIMATOLOGIA E ESTUDO DE CASO
}

\author{
SEVERE RAINFALL EVENTS IN THE JABOATÃO OF GUARARAPES: \\ WEATHER CONDITIONS AND CASE STUDY
}

\author{
Ranyere Silva Nobrega \\ Universidade Federal de Pernambuco \\ ranyere.nobrega@yahoo.com.br \\ Rafhael Fhelipe de Lima Farias \\ Universidade Federal de Pernambuco \\ rafhaelfarias@hotmail.com
}

Resumo: O município de Jaboatão dos Guararapes possui um sitio urbano bastante propício para a ocorrência de desastres naturais com áreas de morro bastante adensadas, assim como as planícies fluviais, ambas ocupadas de maneira irregular. O objetivo deste artigo é analisar a variabilidade da precipitação pluviométrica, com foco nos episódios extremos (positivos) e a sua repercussão na sociedade através da ocorrência de enchentes e/ou inundações, em especial no evento de junho de 2005. Foi realizada a climatologia dos eventos extemos pluviais, análise rítmica climatológica, imagens do satélite GOES e informações da Defesa Civil e de veículos de comunicação para fazer a análise do caso de junho de 2005. Nesse sentido, a técnica dos quantis utilizada para a climatologia dos eventos pluviométricos possibilitou categorizar quantitativamente os volumes de chuva mensal e diário classificados como muito chuvosos e extremamente chuvosos. A distribuição sazonal do número de eventos extremos ao longo do ano, para as categorias muito seco e muito chuvoso não apresentam variação significativa. Ao analisar o caso de junho de 2005 ficou evidente que há comportamento quase constante dos elementos climáticos, com exceção da precipitação. A arritmia foi produzida por um DOL organizado que conseguiu enfraquecer a camada de inversão dos alísios.

Palavras-chave: Ambiente urbano, Impactos meteóricos, Ritmo climático, Enchente.

\begin{abstract}
The Jaboatão dos Guararapes has an urban site quite conducive to the occurrence of natural disasters with very dense hill areas, as well fluvial plain, both occupied illegally. The objetive of this paper is to analyze the variability of rainfall, with a focus on extreme events (positive) and its impact on society through the occurrence of floods, especially in June 2005. Was made of climatology rain extemal events, rhythmic climatological analysis, GOES satellite images and civil defense information and communication vehicles to do the analysis of the case in June 2005. Accordingly, the technique of quantile used to the climatology of the rainfall events allowed categorize quantitatively the volumes of monthly rainfall and daily classified as very rainy and extremely rainy. The seasonal distribution of the number of extreme events throughout the year, for very dry and rainy categories show no significant variation. By analyzing the case of June 2005 it became apparent that there is almost constant behavior of climatic elements, except for precipitation. The arrhythmia was produced by an organized DOL that could weaken the inversion layer of the trade.
\end{abstract}

Keywords: Urban environment, Meteor impacts, Climatic rhythm, Flood. 


\section{INTRODUÇÃO}

Os estudos dos ambientes urbanos, sobretudo das cidades brasileiras, remete à diversidade dos espaços e das características sociais mais marcantes da população em cada um desses ambientes, ou seja, é a expressão social (re)produzida na realidade complexa e transformada, refere-se Lombardo (1985) apud Zanella (2006). Nesse sentido, para Santos (1994), a cidade é um meio ambiente construído, fundamentalmente, desigual, completa Rodrigues (1998). São questões da complexa relação sociedadenatureza que oferecem elevado grau de periculosidade e risco como a poluição, as enchentes, os deslizamentos, a chuva ácida, dentre outros. Tais eventos são respostas ambientais específicas e reflexos evidentes da organização de cada lugar que dimensionam localmente as mudanças ambientais e reproduzem dialeticamente as consequências espaciais de uma totalidade - o ambiente urbano (FEITOSA; NOBBREGA; COELHO JÚNIOR, 2016).

Sob o paradigma da relação sociedade-urbanização, em razão da qual se estabelece esse ambiente, é consenso a afirmação de que a ação do ser humano denota, a partir dessa relação, novos processos, novas estruturas, sobre as quais constitui um sistema de respostas pelo sistema natural que não é passivo às ações da sociedade que dele se apropria (SILVEIRA; SARTORI, 2010). Nessa perspectiva, o fator urbano é uma concretude espacial de relevante expressão desses novos cenários produzidos pelo ser humano na paisagem natural.

A ocupação de planícies aluviais e fundos de vale com a implantação de vias de circulação de trânsito ou mesmo com a construção de edificações, tem sido prática comum em muitas cidades brasileiras, e que possuem capacidade de gerar graves problemas socioambientais, produzido e reproduzido, nos centros urbanos desde a fundação das primeiras cidades brasileiras até os dias atuais e, como exemplo, a expressão do elevado grau de vulnerabilidade as enchentes (LIMA, 2012).

A questão tratada diz respeito também a relação socioeconômica e ambiental verificada basicamente em todo o Brasil, que até meados do século XX configurava um quadro rural. No entanto, os incentivos adotados pela política de modernização atraíram contingente populacional cada vez maior na atividade industrial. Esse processo fez grande parte da população rural passar a residir nas cidades, resultando em migração da população da zona rural, fazendo com que as cidades gradativamente aumentassem em número de habitantes e em importância econômica (CHAVES; LOPES, 2011). Registros mais recentes informam de que a maior parte da população reside nos espaços urbanos, o que acarretou em Mendonça (2004) compreender o século XXI "o século da cidade", já o século XX, por sua vez, teria sido o da urbanização.

Outro fato associado ao aumento e concentração populacional nas cidades foi e continua sendo, a busca por uma melhor condição de vida. Disso, resulta a importância que é dada hoje as cidades, e, com isso, a sociedade contemporânea torna-se predominantemente urbana. Esse fato faz do espaço da cidade, no sentido dado por Christofolleti (1997) um grande mosaico, um grande ecossistema, onde o natural e o construído compartilham um único lócus. Ainda seguindo esse raciocínio, Chaves (2009) argumenta que, apesar de a cidade ser um construto humano subordinado às diversas formas de organização do espaço urbano, sua ambiência retrata a articulação indissociável dos elementos do ambiente natural e do ambiente construído. A natureza faz parte da cidade, mesmo sendo a última, um ambiente modificado, onde na sua construção, o natural foi descaracterizado, a natureza fez-se urbanizada, integrada a cidade para compor o civilizado, reforça Leite (1997) citado por Feitosa et al. (2016).

Associado aos problemas de ordem estrutural, pode-se destacar a influência da variabilidade climática e possíveis aumentos dos desastres naturais. Estudos recentes vêm mostrando que há tendência de concentração para os episódios de dias consecutivos chuvosos e/ou concentração dos eventos diários em Pernambuco, o que acabam por potencializar os desastres naturais (NÓBREGA et al., 2015).

Monteiro (1976) ao propor teorias e técnicas para a fundamentação de clima urbano, elaborou o Sistema de Clima Urbano (SCU), definindo três canais de percepção do clima urbano. O terceiro canal é denominado de Impacto Meteórico, no qual são abordados fenômenos como aguaceiros, tempestades, furacões, entre outros, que ao alcançarem intensidades significativas, podem comprometer a integridade física e social da cidade, perturbando-a e desorganizando-a.

De fato, como o próprio autor menciona, os grandes aguaceiros são desorganizadores eventuais da vida urbana, e necessitam de análise geográfica acurada de diversos atributos urbanos para explicar tais impactos, e para esse estudo é necessário resgatar o passado, a memória da cidade, as transformações urbanas e a análise espacial dos episódios pluviais. Complementando, Viana e Amorim (2009) descrevem 
que estudar o clima das cidades é compreender a complexidade de uma relação bilateral, uma vez que estas, ao se desenvolverem, assumem o papel de agente modificador do meio natural. Dentre todas as transformações ocorridas no ambiente urbano, uma que merece especial atenção é a modificação dos elementos do clima. É neste sentido que o objetivo deste artigo é analisar a variabilidade da precipitação pluviométrica no município de Jaboatão dos Guararapes, com foco em episódios extremos (positivos) e a sua repercussão na sociedade através da ocorrência de enchentes e/ou inundações, em especial no evento de junho de 2005.

\section{MATERIAL E MÉTODOS}

\section{Área de Estudo}

O município de Jaboatão dos Guararapes encontra-se localizado na porção central da Região de Desenvolvimento Metropolitana e mais especificamente na microrregião do Recife (Figura 1). O seu território é limitado ao norte pelo município de São Lourenço da Mata e Recife, ao oeste com Moreno, ao sul com o Cabo de Santo Agostinho e ao leste com o oceano Atlântico. A extensão territorial é de aproximadamente $256 \mathrm{~km}^{2}$ (BDE, 2015).
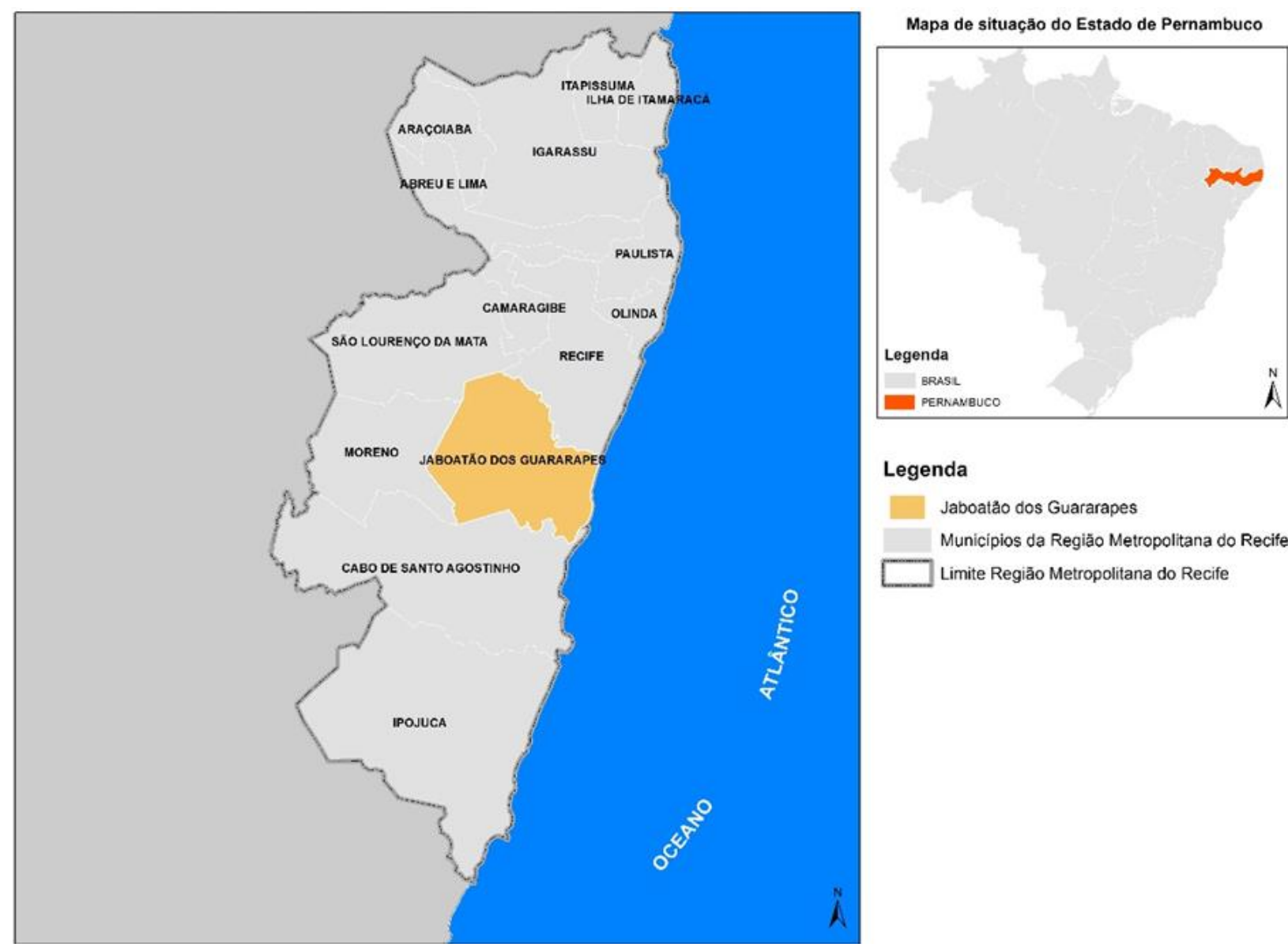

\section{Legenda}

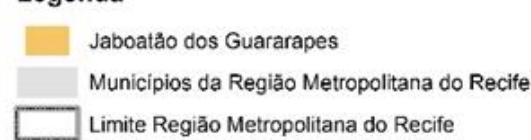

Figura 1: Localização geográfica do município de Jaboatão dos Guararapes, Pernambuco (laranja), pertencente a Região Metropolitana do Recife (cinza).

Municipalmente, Jaboatão dos Guararapes é divido por regiões político-administrativa, sendo ao todo sete: 1. Jaboatão Centro; 2. Cavaleiro; 3. Curado; 4. Muribeca; 5. Prazeres; 6. Praias, e; 7. Guararapes.

A geomorfologia possui, de acordo com Silva et al. (2010), cinco tipos de solos: gleissolos, latossolos amarelos, solos mangue, podzólicos vermelho-amarelos e podzóis hidromórficos, mais a área urbana. Vale ressaltar que a partir do ano de 2006 alguns tipos de solo sofreram modificações com relação a 
sua nomenclatura, entre eles estão os solos do tipo podzólicos e podzóis (ambos encontrados no município de Jaboatão dos Guararapes) passaram a ser chamados de argissolos e espodossolos, respectivamente.

A rede fluvial está inserida dentro do grupo de pequenos rios litorâneos (GL2), sendo o rio Jaboatão o principal curso d' água, desembocando no Oceano Atlântico, na divisa com o município do Cabo. Seu principal afluente é o rio Duas Unas, margem esquerda, represado pela barragem de mesmo nome, única nos limites do município, e considerada de grande importância para o abastecimento da Região Metropolitana do Recife (RMR).

O município está situado numa região de clima tropical, com temperaturas médias entre $32^{\circ} \mathrm{C}$ de máxima e $18^{\circ} \mathrm{C}$ de mínima. $\mathrm{O}$ volume de precipitação médio anual é $1.720 \mathrm{~mm}$, com maior concentração entre maio e agosto, caracterizando o período chuvoso. Os meses de outubro a março o volume diminui consideravelmente, caracterizando o período seco, com setembro e abril os meses de transição entre os períodos distintos (Figura 2).

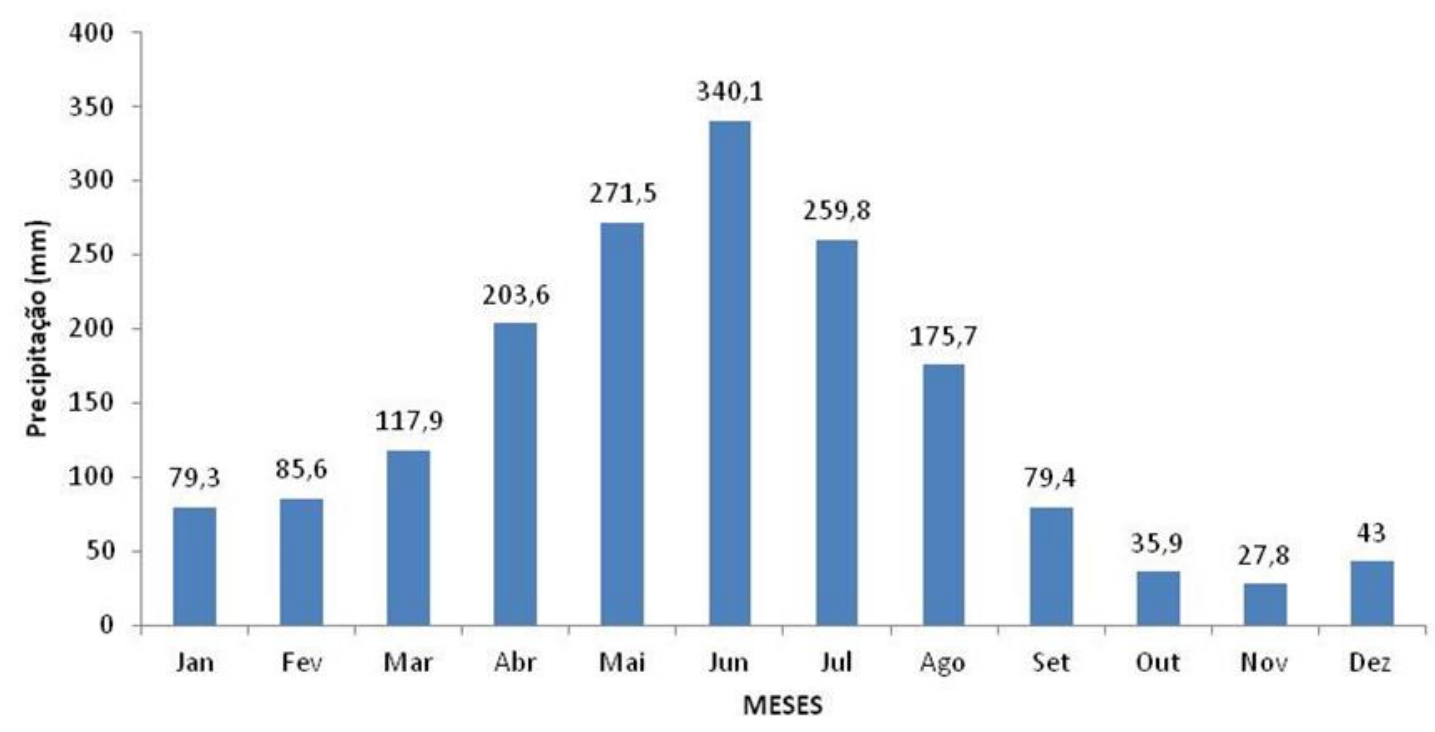

Figura 2: Variabilidade da precipitação média mensal para o período de 1995 a 2014.

Os principais sistemas atmosféricos atuantes são os distúrbios ondulatórios de leste, que em conjunto com a brisa marítima, modulam a maior parte do volume de chuva da estação chuvosa. A influência da Zona de Convergência Intertropical (ZCIT) e os ventos úmidos dos alísios de sudeste, com gênese na alta pressão semipermanente do Atlântico Sul também resultam em consideráveis volumes de chuva, principalmente nos meses de abril e maio. Durante o verão austral, vórtices ciclones de altos níveis e nuvens convectivas são responsáveis por pancadas de chuva, muitas vezes convectivas, configuração típica do período seco, mas de volume mensal reduzido (ao comparar com o período chuvoso) devido o comportamento transiente desse sistema. Em todos os meses do ano são registradas chuvas em Jaboatão dos Guararapes, no entanto, durante a estação seca, é possível ocorrer um único evento pluviométrico que represente todo o acumulado mensal.

Com relação a morfologia urbana, apresenta um sitio urbano bastante propício para a ocorrência de desastres naturais com áreas de morro bastante adensadas, assim como as planícies fluviais, ambas ocupadas de maneira irregular. Desta forma, os desastres naturais que acabam sendo os mais comuns no município são os de natureza hidrológica e geológica, com gênese atmosférica.

\section{Climatologia de eventos extremos de precipitação}

Para a análise da climatologia de eventos extremos de precipitação, optou-se pela técnica dos quantis, que vem sendo amplamente disseminada a partir dos estudos pioneiros iniciados em 1966, na Universidade do Estado do Colorado, com objetivo principal de analisar a ocorrência de anos secos e chuvosos em extensas áreas continentais, especialmente nos Estados Unidos da América. No Brasil, dentro da climatologia, vem sendo utilizada por pesquisadores para categorizar diferentes elementos climáticos, não 
apenas chuva, como também a temperatura do ar e eventos de incursões de massas de ar, como exemplos. Para informações mais detalhadas, incluindo extensa revisão bibliográfica com o uso da técnica pelo Brasil, sugere-se a leitura de Xavier (2002).

A definição do quantil, em termos climatológicos, segundo Xavier (2002) é:

$$
\operatorname{Prob}(\mathrm{X} \leq \mathrm{Qp})=\mathrm{P}
$$

em que $\mathrm{P}$ significa probabilidade, $\mathrm{X}$ corresponde a uma variável aleatória (que no caso da presente foi inserido a precipitação) acumulada em um determinado período de tempo (bimestre, trimestre, semestre, ano) e $\mathrm{Qp}=\mathrm{Q}(\mathrm{p})$ representa o quantil.

As ordens quantílicas (p) propostas são $\mathrm{p}=0,15 ; 0,35 ; 0,65 ; 0,85$, ou então, $15 \% ; 35 \% ; 65 \% ; 85 \%$ que correspondem aos níveis ou categorias: Muito Seco (MS), Seco (S), Normal (N), Chuvoso (C) e Muito Chuvoso (MC), respectivamente. Para o presente estudo, que tem como objetivo detectar possíveis ocorrências de extremos de precipitação (secos e/ou chuvosos) os autores decidiram por utilizar duas categorias a mais, para valores extremos: Extremamente Seco (ES) ordem quantílica de $\mathrm{p}=0,05$ e Extremamente Chuvoso (EC) ordem quantílica de $\mathrm{p}=0,95$. As ordens quantílicas e seus intervalos podem ser observados na Tabela 1.

Tabela 1: Ordens Quantílicas para a precipitação pluviométrica.

\begin{tabular}{ll}
\hline \multicolumn{1}{c}{ CATEGORIAS } & \multicolumn{1}{c}{ INTERVALOS } \\
\hline Extremamente Seco (ES) & $\mathrm{X} \leq \mathrm{Q} 0,05$ \\
Muito Seco (MS) & $\mathrm{Q} 0,05<\mathrm{X} \leq \mathrm{Q} 0,15$ \\
Seco (S) & $\mathrm{Q} 0,15<\mathrm{X} \leq \mathrm{Q} 0,35$ \\
Normal (N) & $\mathrm{Q} 0,35<\mathrm{X}<\mathrm{Q} 0,65$ \\
Chuvoso (C) & $\mathrm{Q} 0,65 \leq \mathrm{X}<\mathrm{Q} 0,85$ \\
Muito Chuvoso (MC) & $\mathrm{Q} 0,85 \leq \mathrm{X}<\mathrm{Q} 0,95$ \\
Extremamente Chuvoso (EC) & $\mathrm{X} \geq \mathrm{Q} 0,95$ \\
\hline
\end{tabular}

Fonte: Xavier (2002).

O período analisado compreende 20 anos de dados, com início em 1999 e término em 2011, obtidos com a Agência Pernambucana de Águas e Clima (APAC).

\section{Análise Rítmica climatológica}

As teorias relacionadas à abordagem dos ritmos da natureza e da sociedade adotadas na pesquisa, elaboradas por Monteiro (1971) sobre a análise rítmica em climatologia, e por Lefebvre (1992) sobre a ritmanálise para a perspectiva da sociedade, convergem na ideia de ritmo enquanto forma de análise e entendimento de processos dinâmicos, no presente caso envolvem o clima e a sociedade (TAVARES, 2010).

Os ritmos do clima são medidos, através da análise da variação pluviométrica, considerando-se que a chuva é o elemento climático que mais interfere na região em estudo, além claro, de ser o elemento atmosférico responsável pela gênese da maioria dos desastres naturais no Brasil.

Para a análise foi utilizada uma planilha Excel, desenvolvida no Laboratório de Climatologia, da Universidade Federal do Paraná. Como saída, são plotados gráficos de diferentes elementos climáticos e massas de ar, para análise conjunta interligando-os à precipitação.

O caso do mês de junho de 2005 foi selecionado para a pesquisa, uma vez que o evento pluviométrico do início do mês foi significativo em termos de intensidade e impactos. Os dados foram obtidos junto ao Instituto Nacional de Meteorologia (INMET) e a APAC. 


\section{Coleta de informações sobre eventos extremos}

Com relação aos impactos decorrentes dos episódios de eventos pluviais extremos, mais especificamente, os eventos de inundações e/ou enxurradas, no município de Jaboatão dos Guararapes, foram coletados dados de diversas fontes de pesquisas: (a) Sistema Integrado de Informações sobre Desastres (S2ID); (b) Coordenação de Defesa Civil, e (c) Arquivo Público Estadual Jordão Emerenciano (APEJE)

O S2ID é um Banco de Dados que integra diversos produtos da Secretária Nacional de Proteção e Defesa Civil - SEDEC - vinculado ao Ministério da Integração Nacional. Tem como objetivo difundir de forma prática os desastres naturais ocorridos em todo território nacional. No Banco de Dados é possível obter informações a nível municipal e estadual dos registros ocorridos, as portarias com finalidade de reconhecimento de estado de emergência assim como o de calamidade pública, fotos, informações jornalísticas, os AVADAN, dentre outros materiais concernentes a desastres naturais. Desta forma, o S2ID acaba se tornando uma fonte de pesquisa bastante importante. As informações podem ser obtidas através do sítio: http://s2id.mi.gov.br/.

A Coordenação de Defesa Civil foi de extrema importância para a coleta das informações sobre os desastres decorrentes das inundações e/ou enxurradas durante junho de 2005 na região de Jaboatão centro. Além das fotos disponibilizadas pela Defesa Civil, também foi disponibilizada o Relatório de Avaliação de Danos (AVADAN) do evento de junho de 2005, documento oficial, no qual é realizada toda a discrição do desastre, área atingida, causa do desastre, danos humanos, materiais, ambientais, prejuízos econômicos, dentre outras informações. O AVADAN juntamente com a Notificação Preliminar de Desastre (NOPRED) foram extintos no ano de 2012 e, ambos foram substituídos por um documento único, o Formulário de Informações Sobre Desastres (FIDE). A Defesa Civil também disponibilizou o seu histórico com o número de vítimas provenientes das inundações e movimentos de massa durante os anos de 2005.

O acervo histórico da repercussão das inundações e/ou enxurradas através dos jornais foi obtido junto ao APEJE, localizado no município de Recife/PE. No APEJE é possível ter acesso a um vasto acervo histórico do estado de Pernambuco, através de exemplares de jornais passados, fotografias, livros, documentos, manuscritos e outros tipos de informações relevante à história de Pernambuco. As consultas podem ser realizadas de forma gratuita.

\section{Mapa da Mancha de Inundação}

Os mapas de mancha de inundação acabam servindo como um importante instrumento para o planejamento urbano das áreas localizadas próximas aos corpos d'água, uma vez que é possível delimitar as áreas atingidas por inundações passadas.

O mapa da mancha de inundação da área estudada foi feito a partir da realização de trabalhos de campos, nos quais foi possível obter as áreas atingidas pela inundação do ano de 2005 através das informações dos moradores mais antigos e das observações realizadas in loco. $\mathrm{O}$ trecho escolhido abrange a parte conhecida como Jaboatão Velho, uma vez que a sede administrativa do município foi transferida para o bairro de Prazeres (Regional 5). Este trecho abrange quatro bairros: 1. Centro; 2. Vargem Fria; 3. Vista Alegre e; 4. Vila Rica

\section{RESULTADOS E DISCUSSÃO}

Para a análise da climatologia dos extremos pluviais optou-se por duas escalas temporais, a mensal e a diária, uma vez que os volumes diários são importantes para os estudos de impactos meteóricos. Primeiramente, foram calculadas as médias, máximas e mínimas mensais, e posteriormente, utilizando a técnica dos quantis, a precipitação foi categorizada com base nos limites quantílicos $15 \%$ e $85 \%$, como muito seco $(\mathrm{Q} 0,15)$ e muito chuvoso $(\mathrm{Q} 0,85)$, conforme pode ser observada na Tabela 2. Para os volumes máximos e mínimos, foram destacados os anos do registro, dentro de parênteses.

Devido a considerável variabilidade temporal da precipitação, característica do Nordeste brasileiro, ao utilizar a apenas a média como estatística descritiva para a climatologia, há a possibilidade de incorrer em análise errônea. Como exemplo, durante abril de 2001, o acumulado mensal foi de 13mm, enquanto em 2011 foi de $758 \mathrm{~mm}$. A média mensal é de $204 \mathrm{~mm}$ e desvio padrão de $\pm 193 \mathrm{~mm}$, valor considerável, corroborando com a importância do uso da técnica dos quantis, conforme Xavier (2002). 
Tabela 2: Precipitação média, máxima e mínima mensal e categorização quantílicas para o volume de chuva mensal considerado muito seco $(\mathrm{Q} 0,15)$ e muito chuvoso $(\mathrm{Q} 0,85)$

\begin{tabular}{lcccccc}
\hline & Jan & Fev & Mar & Abr & Mai & Jun \\
\hline Méd. & 79 & 86 & 118 & 204 & 272 & 340 \\
Máx & $238(04)$ & $199,2(02)$ & $329,8(08)$ & $758,3(11)$ & $638,6(11)$ & $615,5(05)$ \\
Mín & $3,6(97)$ & $1,3(95)$ & $22,6(98)$ & $13,3(01)$ & $17,8(01)$ & $93,4(99)$ \\
$\mathbf{Q}_{\mathbf{0}, \mathbf{1 5}}$ & 15 & 17 & 60 & 30 & 102 & 157 \\
$\mathbf{Q}_{\mathbf{0} 85}$ & 175 & 170 & 151 & 315 & 434 & 541 \\
\hline & Jul & Ago & Set & Out & Nov & Dez \\
\hline Méd. & 260 & 176 & 79 & 36 & 28 & 43 \\
Máx & $493,4(00)$ & $412,4(00)$ & $304,9(14)$ & $165,2(14)$ & $68(13)$ & $146(00)$ \\
Mín & $55(97)$ & $14,9(95)$ & $0,2(95)$ & $0,1(06)$ & $0(06)$ & $0(01 / 06)$ \\
$\mathbf{Q}_{\mathbf{0}, \mathbf{1 5}}$ & 175 & 76 & 19 & 6 & 3 & 1 \\
$\mathbf{Q}_{\mathbf{0}, \mathbf{8 5}}$ & 384 & 257 & 147 & 52 & 60 & 77 \\
\hline
\end{tabular}

Com os resultados apresentados na Tabela 2, foi realizado o levantamento do número de ocorrências média de eventos ao longo de cada mês para as categorias Q15 e Q85, observados na Tabela 3. Apesar do volume de chuva, ao comparar os distintos períodos ao longo do ano, há distribuição muito próxima do número de ocorrências de eventos extremos de chuva, tanto para a ausência, quanto para a ocorrência do elemento climático.

Na Tabela 3 tem-se o volume diário para as categorias muito seco, muito chuvoso e extremamente chuvoso (Q95). Os valores são importantes parâmetros para a análise da ocorrência de eventos extremos no município, que pela morfologia urbana, modo de uso e ocupação da terra, é suscetível para enchentes, alagamentos urbanos e movimentos de massa, possibilitando que os resultados possam ser utilizados para tomadas de decisões.

Durante o período chuvoso há ocorrências de dias consecutivos de chuva (diferente do período seco, que as chuvas são intermitentes, além da ocorrência de veranicos (SOARES; NÓBREGA, 2010). A continuidade dos eventos pluviométricos impacta mais severamente no centro urbano. De fato, a ocorrência de mais de dois dias com volume de chuva superior a 58,6mm, durante o mês de junho, valor categorizado com extremamente chuvoso (Tabela 4) ocorre em alguns anos da série estudada (dados processados, mas não apresentados nesse trabalho), como no caso dos primeiros dias de junho de 2005 . Nesse caso, o problema ambiental urbano, inicializado pelas manifestações episódicas de precipitações intensas, evidenciam ainda mais a crescente diferenciação social presente nas cidades, podendo ser, portanto, interpretadas como um problema ambiental urbano, corroborando com Collischonn (2010).

Tabela 3: Número de ocorrências média ao longo dos meses de eventos muito seco $(\mathrm{Q} 0,15)$ e eventos muito chuvoso $(\mathrm{Q} 0,85)$

\begin{tabular}{lllllllllllll}
\hline Q(p) & Jan & Fev & Mar & Abri & Mai & Jun & Jul & Ago & Set & Out & Nov & Dez \\
\hline $\mathbf{0 , 1 5}$ & 3 & 3 & 3 & 3 & 3 & 3 & 3 & 4 & 3 & 4 & 4 & 4 \\
$\mathbf{0 , 8 5}$ & 3 & 4 & 3 & 4 & 3 & 3 & 3 & 3 & 3 & 3 & 3 & 3 \\
\hline
\end{tabular}

Tabela 4: Volume de chuva diário categorizado em muito seco $(\mathrm{Q} 0,15)$, muito chuvosos $(\mathrm{Q} 0,85)$ e extremamente chuvosos $(\mathrm{Q} 0,95)$

\begin{tabular}{lllllllllllll}
\hline $\mathbf{Q}(\mathbf{p})$ & Jan & Fev & Mar & Abr & Mai & Jun & Jul & Ago & Set & Out & Nov & Dez \\
\hline $\mathbf{0 , 1 5}$ & 0 & 0 & 0 & 0 & 0 & 0 & 0 & 0 & 0 & 0 & 0 & 0 \\
$\mathbf{0 , 8 5}$ & 3,4 & 4 & 6,9 & 12,1 & 19,5 & 21,6 & 17,7 & 10,5 & 4 & 1,7 & 0,5 & 1,3 \\
$\mathbf{0 , 9 5}$ & 12,9 & 16,9 & 20,1 & 35,7 & 42,5 & 58,6 & 38,9 & 24,2 & 12,8 & 6,4 & 5 & 6,8 \\
\hline
\end{tabular}

Além da suscetibilidade da morfologia urbana, é importante destacar a conurbação entre Jaboatão dos Guararapes e Recife, produzindo adensamento urbano maior do que ao analisar apenas uma cidade. Nesse sentido, Zanella (2006) e Monteiro e Mendonça (2003) apontam que a relação urbanização e 
precipitação constituem um processo de causa-efeito, no qual a mancha urbana pode induzir maior atividades convectivas. De fato, a morfologia urbana, sobretudo a rugosidade, e as ilhas de calor forçam a ascensão do ar em um processo convectivo, que em conjunto com a atuação de sistemas atmosféricos, como os distúrbios ondulatórios de leste, potencializam o efeito convectivo, produzindo precipitações mais volumosas e de maiores intensidades. Além disso, ainda segundo os autores supracitados, a poluição do ar pode favorecer o aumento dos núcleos higroscópicos, fator preponderante para a condensação do vapor de água influenciando e muito no tamanho das gostas da chuva.

Os volumes de precipitação categorizados como muito chuvoso e extremamente chuvoso são importantes para que a Defesa Civil inicie os procedimentos de medidas de segurança para a população vulnerável aos episódios. Por exemplo, em junho, o volume de $21,6 \mathrm{~mm}$ é classificado como muito chuvoso, mas, órgãos de meteorologia costumam adotar $30 \mathrm{~mm}$ diária como chuva de intensidade moderada. Além disso, a sequência de dias chuvosos pode ser mais problemática do que um episódio de chuva de forte intensidade (pela APAC, acima de 50mm), uma vez que a capacidade de campo do solo pode ser atingida rapidamente durante o período chuvoso, e a água pluvial não mais infiltrar no solo. Vale ressaltar que, a necessidade dessa categorização surgiu de diálogos com a própria Defesa Civil.

Somado a isso, Nóbrega et al. (2015) encontraram que há tendência de redução do volume de precipitação anual na Região Metropolitana do Recife, no entanto as chuvas estão mais concentradas em menos dias de precipitação, o que pode potencializar os impactos na área urbana.

\section{O evento pluviométrico dos dias 01, 02 e 03 de Junho de 2005}

O município de Jaboatão dos Guararapes, principalmente a região conhecida como Jaboatão Velho, foi afetado por intensas chuvas durante os três primeiros dias de junho de 2005, causando diversos transtornos ao sítio urbano. Os totais diários acumulados durante os dias 01,02 e 03 , foram de $48 \mathrm{~mm}, 71 \mathrm{~mm}$ e $91 \mathrm{~mm}$, respectivamente, acumulando o volume de $209 \mathrm{~mm}$, representando $61 \%$ da média para o mês de junho (340mm). Em todos os dias, comparando com a Tabela 4, a chuva é categorizada como episódio muito chuvoso, e nos dias 02 e 03, extremamente chuvoso.

Na Figura 3 tem-se o ritmo das temperaturas do ar compensada, máxima e mínima, umidade relativa do ar média, precipitação diária, velocidade e direção do vento e massa de ar atuante, simplificando o modelo de análise rítmica proposto por Carlos Augusto Monteiro. A simplificação fez-se necessária devido a falta de todos os dados meteorológicos utilizados na análise rítmica, como pressão atmosférica.

Não há variação significativa nos elementos climáticos temperatura e umidade do ar, velocidade e direção do vento, tampouco a dinâmica de massas de ar. Este comportamento é característico do leste do nordeste brasileiro. Não há incursões de massas de ar diferentes ao longo do ano, apenas em casos eventuais (para não dizer excepcionais). O que acaba produzindo a arritmia climática e a resposta meteórica é a interação entre oceano Atlântico, continente adjacente, circulação primária e secundária da atmosfera.

De fato, o ENEB (Leste do Nordeste do Brasil) está inserido na região de inversões térmicas dos ventos alísios, condição dinâmica que acaba por produzir precipitação associada, na maioria das vezes, com nuvens rasas (como stratus, stratocumulus e cumulus rasos) (SCHUBERT et al. (1995). Essa condição dinâmica, associada a térmica, resulta em precipitações quase que diárias durante a estação chuvosa, principalmente forçada pela brisa marítima, ocorrendo, sobretudo, entre 20:00hs às 09:00hs do dia seguinte (fonte própria, trabalho em produção). Um sistema meteorológico bem organizado é suficiente para enfraquecer a camada de inversão dos alísios, intensificar a convecção e aumentar a instabilidade atmosférica ao se aproximar da costa (HOUNSOU-GBO et al., 2014).

Com a atuação da massa de ar Tropical Atlântica durante todo o mês, optou-se por analisar imagens do satélite GOES 13, canal infravermelho, durante o dia 02 de julho (Figura 4) para identificar o sistema e seus estágios. Estão destacadas três fases do evento, gênese (azul), maturação (vermelha) e dissipação (verde), baseada na metodologia utilizada por Machado et al. (2012). O sistema foi identificado como distúrbio ondulatório de leste (a análise foi suprimida por não fazer parte dos objetivos desse artigo), com gênese no dia 01 de junho, às 21:00hs (02/06 às 00:00hs UTC - círculo azul), entrando em estágio de maturação a partir das 01:00hs local (02/06 às 04:00hs UTC - círculo vermelho), quando o sistema começa a adquirir aspecto circular, característico da atividade convectiva associada ao distúrbio. O sistema permanece localizado a barlavento do Planalto da Borborema e entra em estágio de dissipação a partir das 18:00hs local (02/06 às 21:00hs UTC - círculo azul). 


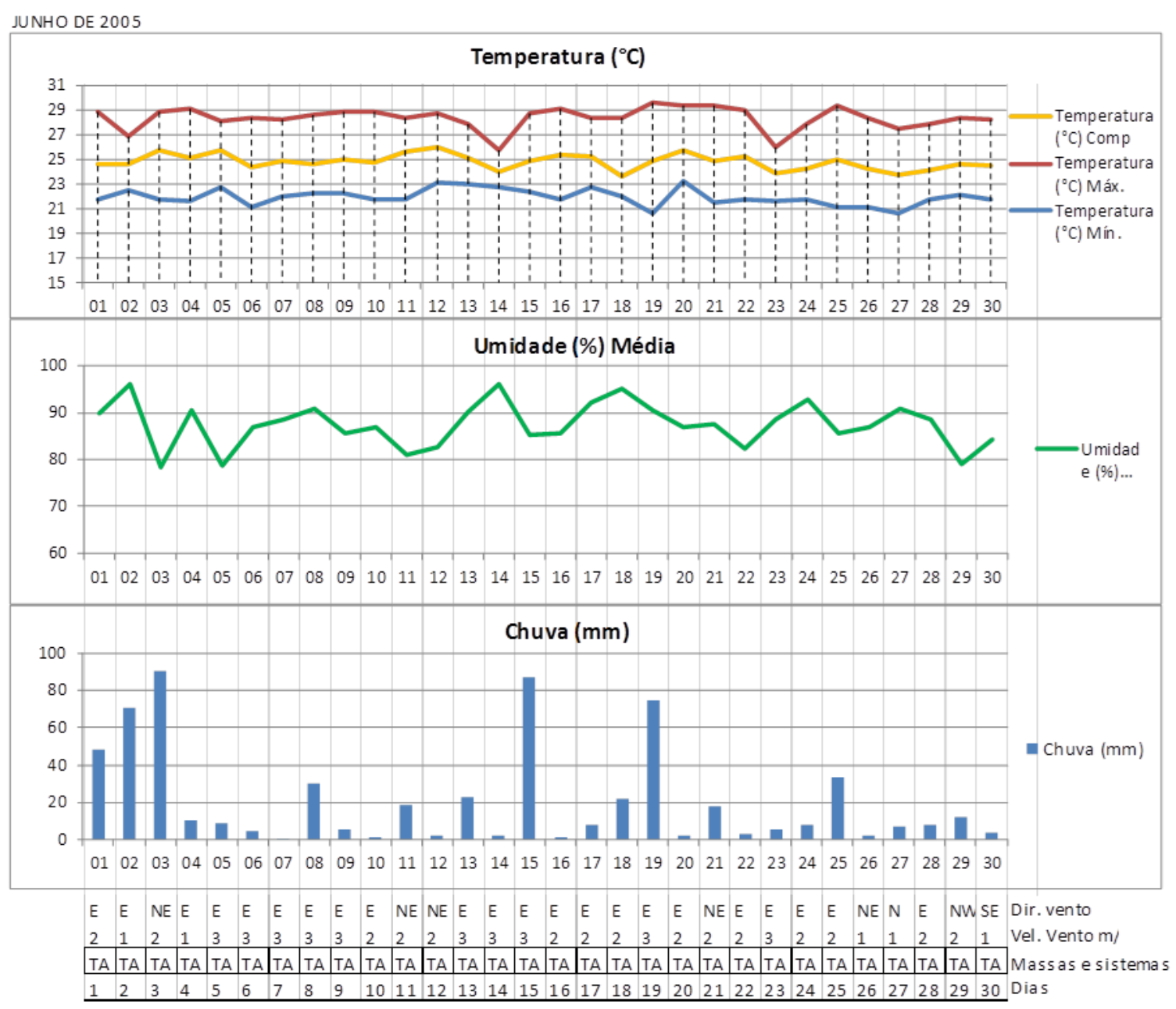

LEGENDA
FF. Frente Fria
TA. Massa Tropical Atlântica
RF. Repercursao de Frente
TC. Massa Tropical Continental
PA. Massa Polar Atlântica
EC. Massa Equatorial Continental

Figura 3: Análise rítmica simplificada para Jaboatão dos Guararapes, de junho de 2005.

De acordo com o levantamento da Defesa Civil municipal de Jaboatão dos Guararapes, e relatada no formulário de Avaliação de Danos - AVADAN, a partir das 14 horas do dia 02 de junho com as fortes precipitações pluviométricas ocorridas na Região Metropolitana do Recife, onde se registrou um acumulado de 161,4 mm em 48 horas (01 e 02/06/2005), o municipio do Jaboatão dos Guararapes, localizado a 19,4 km de distância da capital, foi fortemente afetado pelo transbordamento dos leitos dos rios duas Unas e Jaboatão.

No mesmo formulário há o registro das ocorrências e impactos do evento pluviométrico. Mais de 6.000 pessoas foram desalojadas e aproximadamente 4.500 ficaram desabrigadas. Foram registrados 20 óbitos e 3 pessoas desaparecidas (durante o evento) e 76 feridas. Afetadas diretamente totalizaram 91.596 pessoas.

O comércio, indústria e prestação de serviços também tiveram grandes prejuízos, com mercadorias comercializadas nos mercados públicos destruídas, estruturas físicas danificadas. O comércio estava em estoque porque se tratava de fim de semana, plantações de agricultura destruídas, grãos e tubérculos apodrecidos. Como o alagamento chegou à zona rural, também ocorreu prejuízos na pecuária, com pastos destruídos, apriscos e morte de animais. Na Figura 5 são observadas fotos dos danos produzidos pelo evento. 


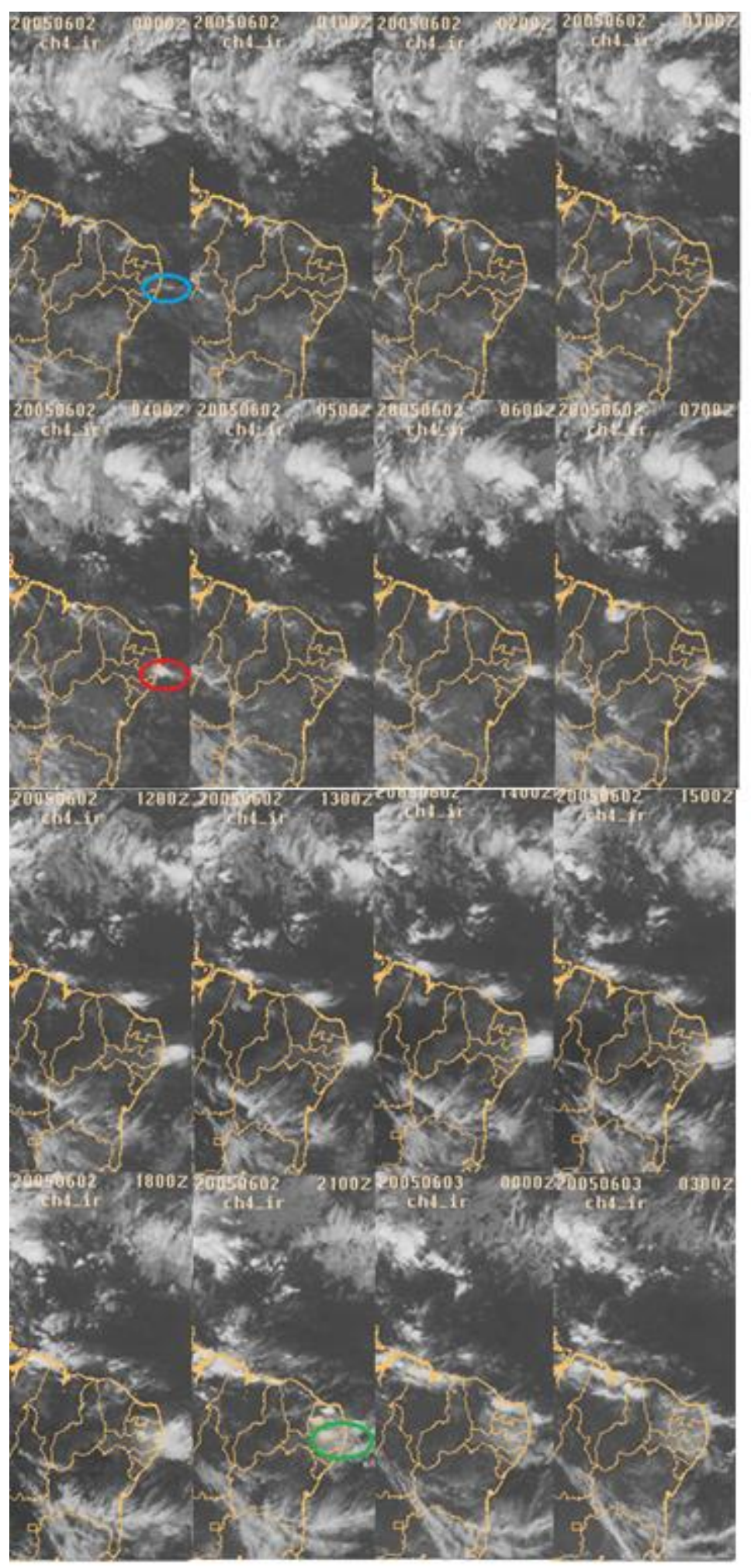

Figura 4: Imagens do satélite GOES 13 para o dia 02 de junho de 2005, destacando o distúrbio ondulatório de leste em três fases - gênese (azul), maturação (vermelho) e dissipação (verde).

Os danos também foram registrados em matérias pelos veículos de comunicação, como na Figura 6. Castro Junior et al. (2010) comentaram que o jornalismo pode contribuir com os gestores públicos, sociedade e até a ciência em casos como urbanização e enchentes, com leituras sobre adequações urbanísticas. Na capa do Jornal do Commércio no dia 03 de junho de 2005 chama a atenção a manchete "Agonia e morte" e também a foto de um veículo retirado do rio Jaboatão. 


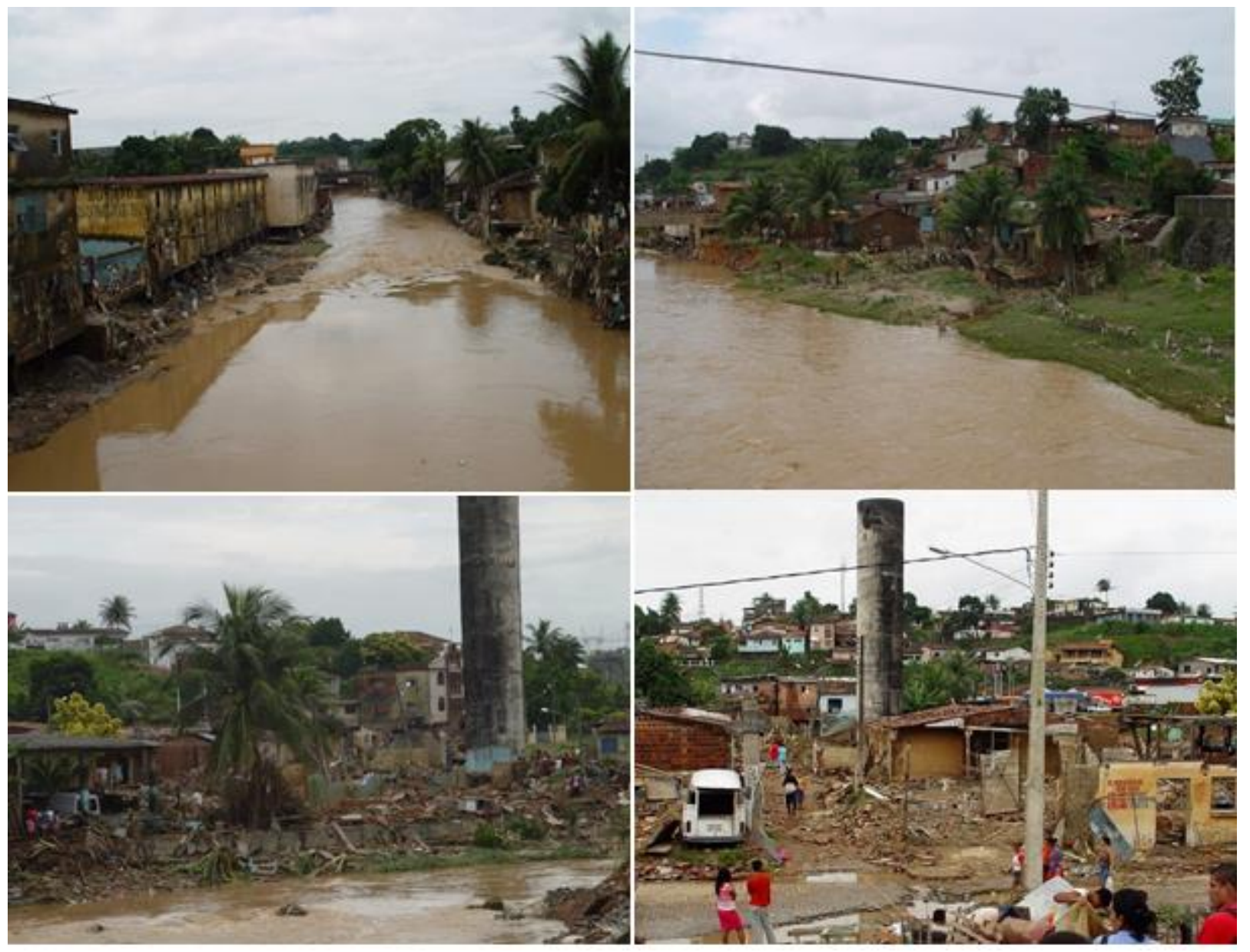

Figura 5: Fotos dos danos provocados pelo evento meteorológico dos dias 01 a 03 de junho de 2005, na margem do rio Jaboatão, município de Jaboatão dos Guararapes, PE. Fonte: Defesa civil de Jaboatão dos Guararapes.
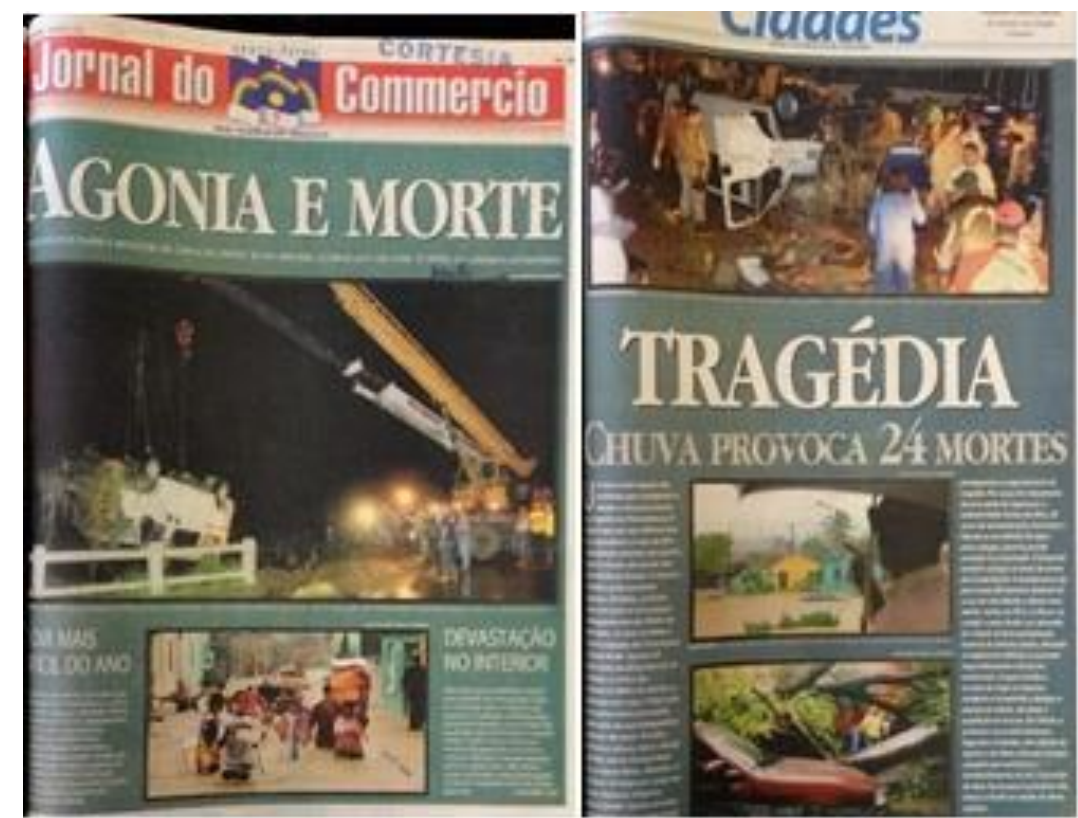

Figura 6: Capa e o caderno cidades do Jornal do Commércio no dia 03/06/2005 repercuntindo os transtornos no município de Jaboatão dos Guararapes provocados a partir das intensas chuvas. Fonte: Jornal do Commercio. 
Países que investem em política e planos de prevenção tendem a apresentar menor número de casos e danos econômicos e sociais, sendo que a prática de prevenir tende a amenizar os impactos e aumentar a resiliência do espaço (NASCIMENTO; FIALHO, 2009, p. 15). Recentemente, uma lei foi publicada no Brasil, criando a Política Nacional de Proteção e Defesa Civil - PNPDEC, dispondo sobre o Sistema Nacional de Proteção e Defesa Civil - SINPDEC e o Conselho Nacional de Proteção e Defesa Civil CONPDEC, autorizando a criação de sistema de informações e monitoramento de desastres. Um passo legal importante para a criação de sistemas de informações e monitoramento de desastres naturais.

De fato, a relação morfologia urbana e transformações espaciais em conjunto com eventos extremos de precipitação torna-se uma ameaça à vida humana, na medida em que áreas sujeitas a alagamentos e enchentes colocam em risco a população que ocupa áreas indevidas. A dinâmica do crescimento urbano de Jaboatão dos Guararapes favorece situações caóticas e preocupantes durante o período de chuva, causadas por impactos meteóricos do campo pluviométrico. O conhecimento da climatologia de eventos extremos vem, então, somar com as informações hidrogeográficas, morfológicas e da dinâmica urbana, subsidiando tomadas de decisões dos atores públicos, comunitários.

\section{CONCLUSÕES}

O objetivo principal deste trabalho foi analisar a variabilidade da precipitação pluviométrica no município de Jaboatão dos Guararapes, com foco nos episódios extremos (positivos) e a sua repercussão na sociedade através da ocorrência de enchentes e/ou inundações, em especial no evento de junho de 2005. Nesse sentido, a técnica dos quantis utilizada para a climatologia dos eventos pluviométricos possibilitou categorizar quantitativamente os volumes de chuva mensal e diário classificados como muito chuvosos e extremamente chuvosos.

A distribuição sazonal do número de eventos extremos ao longo do ano, para as categorias muito seco e muito chuvoso não apresentam variação significativa. Ao analisar o caso de junho de 2005 ficou evidente que há comportamento quase constante dos elementos climáticos, com exceção da precipitação. A arritmia foi produzida por um distúrbio ondulatório de leste organizado que conseguiu enfraquecer a camada de inversão dos alísios.

\section{AGRADECIMENTOS}

Agradecemos a Defesa Civil Municipal de Jaboatão dos Guararapes por despertar a pesquisa através da demanda, bem como pela disponibilidade ao acesso de informações. Agradecemos a Fundação de Amparo à Ciência e Tecnologia do Estado de Pernambuco pelo fomento à pesquisa. Agradecimento especial aos colegas Prof. Edson Fialho (presidente da ABCLIMA) e Prof. Emerson Galvani (membro do Conselho Editorial da Revista do Departamento de Geografia) pelo convite em contribuir com o volume em comemoração os 40 anos do lançamento da obra Teoria e Clima Urbano do Professor Carlos Augusto de Figueiredo Monteiro.

\section{REFERENCIAS}

CASTRO JUNIOR, B.; MOREIRA, S.; DOS SANTOS, M.A.B.B. Interfaces entre o jornalismo e urbanização: os problemas da drenagem pluvial nos centros urbanos. Fragmentos de cultura, v. 20, n. 7/8, p. 455-464. 2010.

CHAVES, S.V.V.A. Vulnerabilidade socioambiental em Teresina, PI. Dissertação de Mestrado. Programa de Desenvolvimento e Meio Ambiente. Teresina: UFPI, 2009.

CHAVES, S.V.V.; LOPES, W.G.R. A vulnerabilidade socioambiental em Teresina, Piauí, Brasil. Revista geográfica da América Central. Número Especial EGAL, 2011. Costa Rica, p. 1-17. 2011.

CHRISTOFOLETTI, A. Impactos no meio ambiente ocasionado pela urbanização no mundo tropical. In: SOUZA, M. A. et al. O novo mapa do mundo - natureza e sociedade de hoje: uma leitura geográfica. São Paulo: Hucitec, 1997.

FEITOSA, M.S. Enchentes do rio Poti e vulnerabilidades socioambientais na cidade de Teresina-PI. Tese de Doutorado. Universidade Federal de Pernambuco, Recife, PE. 229p. 2014. 
FEITOSA, M.S.S.; NÓBREGA, R.S.; COELHO JÚNIOR, J.M. Vulnerability environmental and flood risk in rio Poti, Teresina, Brazil. Revista Geama, v.5, n.1, p. 111-122. 2016.

HOUSOU-GBO, G.A.; ARAÚJO, M.; BOURLÈS, B.; VELEDA, D.; SERVAIN, J. Tropical atlantic contributions to strong rainfall variability along the Northeast Brazilian Coast. Advances in meteorology, v. 2015, p. $1-13.2015$.

LEFEBVRE, H. Éléments de rythmanalyse - Introduction à la connaissance des rythmes, Syllepse, Paris Monteiro, C.A.F. 1971, Análise rítmica em climatologia, Climatologia, 1, IGEOG/USP, São Paulo. 1992.

LEITE, M.A.F.P. A natureza e a cidade: rediscutindo suas relações. In: SOUZA, M. A. et al. O novo mapa do mundo - natureza e sociedade de hoje: uma leitura geográfica. São Paulo: Hucitec, 1997.

LIMA, A.P. Análise de impactos associados à precipitação na cidade de São Carlos/SP. Dissertação de Mestrado. Programa de Pós-graduação em Geografia da FCT/Unesp, Presidente Prudente, 177p. 2012.

MACHADO, C.C.C.; NÓBREGA, R.S.; OLIVEIRA, T; H.; ALVES, K.M.A.S. Distúrbio ondulatório de leste como condicionante a eventos extremos de precipitação em Pernambuco, Revista brasileira de climatologia, v. 11, p. 146-188, Jul/Dez. 2012.

MENDONÇA, F. (org); MONTEIRO, C.A.F. et. al. (autores). Impactos socioambientais urbanos. Curitiba, PR: Ed. UFPR, 2004.

MONTEIRO, C.A. de F. Teoria e Clima Urbano. São Paulo: Universidade de São Paulo/ Instituto de Geografia, 181p. (Série Teses e Monografias n² 25) 1976.

MONTEIRO, C.A.F.; MENDONÇA, F. Clima Urbano. São Paulo: contexto, 2003.

NASCIMENTO, R.A.; FIALHO, E.S. Análise das estratégias emergenciais do Governo Federal para amenizar os impactos pluviais em Minas Gerais entre 2006 e 2008. In: SIMPÓSIO DE GEOGRAFIA APLICADA, 13, Viçosa, 2009. Anais..., Minas Gerais: UFV, CD-ROM, 2009.

NÓBREGA, R.S.; FARIAS, R.F.L.; DOS SANTOS, C.A. Variabilidade temporal e espacial da precipitação pluviométrica em Pernambuco através de índices de extremos climáticos. Revista brasileira de meteorologia, v.30, n.2, p. 171 - 180, 2015.

RODRIGUES, A.M. Produção e consumo do e no espaço: problemática ambiental urbana. São Paulo: Hucitec, 1998.

SILVA, F.B.R.; SILVA, M.A.V.; BARROS, A.H.C.; et al. Zoneamento agroecológico de Pernambuco ZAPE. Recife: Embrapas Solos - Unidade de Execução de Pesquisa e Desenvolvimento - UEP. Zape Digital. CD-ROM. 2010.

SILVEIRA, R.D.; SARTORI, M.G.B. Relação entre tipos de tempo, eventos de precipitação extrema e inundações no espaço urbano de São Sepé - RS. Revista brasileira de climatologia, v.7, ano 6, p. 150 163. 2010.

SOARES, D.B.; NÓBREGA, R.S. Análise espacial e climatológica da ocorrência de veranicos no sertão de Pernambuco. Revista de geografia (Recife) v. 27, n. 1, p. 95 - 106. 2010.

TAVARES, R. Imbricações entre os ritmos do clima e os ritmos da urbanização na formação de risco e vulnerabilidade socioambientais a deslizamentos de terra na serra do mar - Ubatuba/SP. Tese de Doutorado (UFPR), Curitiba, 263p. 2010.

VIANA, S.S.M.; AMORIM, M.C. de C.T. O clima urbano em Teodoro Sampaio/SP: Episódios de verão. Revista Brasileira de Climatologia / Associação Brasileira de Climatologia, Presidente Prudente: ABClima, Ano 5, n.5, p. 41-54, 2009.

XAVIER, T.M.B.S. A Técnica dos quantis e suas aplicações em Meteorologia, Climatologia e Hidrologia, com ênfase para as regiões brasileiras. Brasília: Thesaurus, 143p. 2002.

ZANELLA, M.E. Inundações Urbanas em Curitiba/PR: impactos, riscos e vulnerabilidade socioambiental no bairro Cajuru. Tese de Doutorado (UFPR), Curitiba, 272p. 2006. 